\title{
UAV application for assessing rainforest structure in Ngoc Linh nature reserve, Vietnam
}

\author{
Dung Ngo ${ }^{1, *}$, Hoi Nguyen ${ }^{1}$, Cuong Dang ${ }^{1,2}$, and Sergey Kolesnikov ${ }^{2}$ \\ ${ }^{1}$ Institute of Tropical Ecology, Vietnam-Russian Tropical Centre, 63 Nguyen Van Huyen Str., Hanoi, \\ Vietnam. \\ ${ }^{2}$ Academy of Biology and Biotechnologies, Southern Federal University, 194/1 Stachki prospekt, \\ Rostov-on-Don, Russia.
}

\begin{abstract}
Classifying and evaluating the structure of tropical forest plant biomes based on up-to-date remote sensing data, remains a great challenge due to the species diversity, changes in the stages of seasonal growth. Remote sensing has long been a useful tool for classification and assessment of vegetation. For data from unmanned aerial vehicles (UAVs), the ability to receive high-resolution data also partly solves this problem. The development of vegetation based on natural conditions includes: topographic, geomorphology, geologic conditions, climate, human impacts. Based on the red-green-blue colour model (RGB) obtained from UAV, analysis of VARI (visible atmospherically resistant Index) and TGI (triangulation greenness index), combined with the development characteristics of each group and type of biomes on different topography and geologic types, the researchers were able to give some characteristics of some tropical forest vegetation in Ngoc Linh Nature Reserve, Kon Tum province, Vietnam.
\end{abstract}

\section{Introduction}

The sustainable use, preservation and development of forest resources are ones of the important issues on a global scale when the whole humankind is actively coping with climate change and environmental degradation [1]. In particular, tropical forests with high biodiversity are a key component in climate control, minimizing the negative impacts of climate change and providing ecological services [2].

Evaluating the reserves and structure of the forest plants is an important content in building the basic proposals of forest conservation measures [3, 4]. With the development of science and technology, the application of smart devices in surveying, classifying and monitoring plant resources has been increasingly expanded, becoming one of the most important tools today [5-7]. In recent years, the geodesy and the geodetic technology, as well as the maps- and remote sensing technologies in the world have gained great achievements. Remote sensing has long been a widely used tool in almost every field, from meteorological forecasting, topical mapping, agroforestry to geology, environmental monitoring, flora and fauna control as well as urban research [8-10]. Accordingly, the

* Corresponding author: ngotrungdung266@gmail.com 
classification, monitoring and conservation of forest resources are also the fields in which the remote sensing technology has been widely applied $[11,12]$. Over time, remote sensing technology has been further improved, by improving the quality of sensors that receive infrared, near-infrared, visible light as well as improving resolution that helps increase accurate intensity of image classification [13]. Remote sensing image group has been improved in quality, multi-spectral, multi-data source, multi-time, multi-resolution to conduct closer and more accurate classification and monitoring of forest resources [14].

Unmanned aerial vehicle (UAV) is one of the most remarkably developed remote sensing technologies in the past few years [7]. All the functions such as planned flight, working at a low height and high-resolution images, along with low functioning budget, ease of use as well as flexibility in working time have turned UAV into the most useful tool for surveying as well as in-reality mapping. Compared with Landsat and SPOT satellite images with spatial resolution of $30 \mathrm{~m}$ and $1.5 \mathrm{~m}$ respectively (for SPOT 6 full-colour PAN images), the image data of UAV has a high-quality resolution of about some centimetres depending on ceiling, while not affected by haze. Moreover, the flexibility in working time of UAV is also a great advantage, especially for crop monitoring, crop fluctuations of vegetation, of agroforestry or environmental monitoring [5, 6, 14, 15]. In researching on conservation, in respects of development of forest resources and biodiversity, UAV has been applied quite a lot in countries around the world such as Brazil, USA, China, Russia, Ethiopia. [7, 16, 17]. In studies in tropical forests, UAV has been applied in monitoring, classifying and describing a number of plant indicators and estimating forest cover $[18,19]$. However, the application of UAV in plant classification research, forest monitoring, monitoring of tropical forest fluctuations with large topographic cleavage as in Vietnam has hardly been conducted, causing difficulties for the management and conservation processes.

Chlorophyll quantity and plant canopy cover are of important values for remote sensing using in classification and monitoring of forest plants. In particular, the triangular greenness index (TGI) represents the green index based on the area of the triangles surrounding the spectral characteristics of chlorophyll [20]. Visible atmospherically resistant index (VARI) is designed to emphasize vegetation in the visible portion of the spectrum [21]. For inexpensive UAV devices, most cameras only offer image data in the visible light range, thus taking advantage of the indicators using $670 \mathrm{~nm}$ (R670), $550 \mathrm{~nm}$ (R550), and $480 \mathrm{~nm}$ (R480) has been found to be suitable [22].

The TGI and VARI indicators reflect quite clearly about the vegetations surveyed. However, in order to assess the stability and sustainability of vegetation types, it is necessary to have appropriate methods of statistical analysis and data processing. Statistical analysis is a method to collect data and detect the models and trends of subjects in research. Statistical analysis is widely used in science, from natural sciences to social sciences. In research and conservation of forests and biodiversity, statistical analysis is used as a tool with different purposes.

The first application of statistics in conservation research and sustainable development is statistical analysis of biodiversity. In biodiversity research, researchers often collect species components that can be tabulated as numbers, also known as data (singular = datum). Biodiversity research introduces several different types of data. Many important measurements include numbers (for frequency) and measurements describing characteristics (length, quantity, etc.). Data from a sample is often used to calculate estimates of the population values (mean, mode, and median) and other data describing the dispersion around those values (range, variance and standard deviation) [23]. 


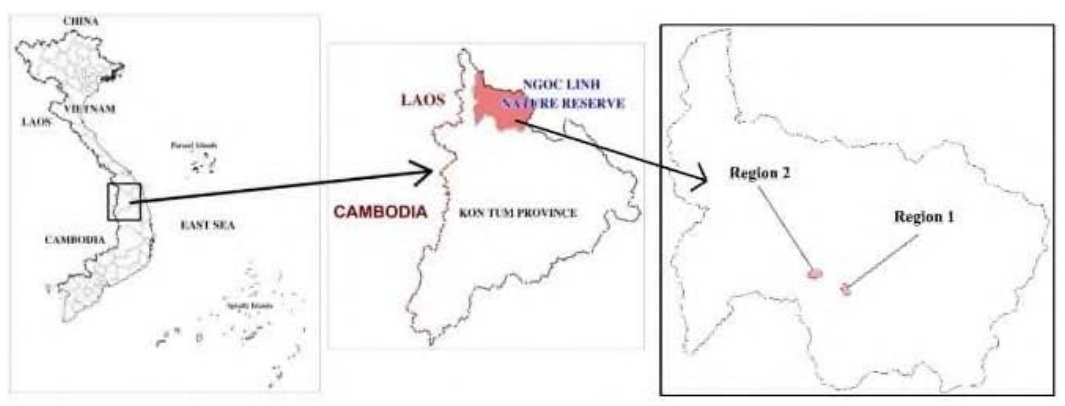

Fig. 1. Location of the study area.

In order to reach the goal of preserving and maintaining the population in landscape units, the structural links between habitats need to be preserved over time. Researchers need to develop quantitative measures of spatial landscape connections; that characterize the extent of how the landscape interferes or facilitates the movement of other subjects. Therefore, the application of statistical analysis methods to the TGI and VARI indicators in the study of the sustainability of vegetation is considered reasonable for areas with high diversity of vegetation such as tropical forests.

Ngoc Linh Nature Reserve with Ngoc Linh mountain peak of $2598 \mathrm{~m}$ above sea level, is a place to preserve many rare and precious gene sources, one of the four very large and endemic treasures of biodiversity of Vietnam. This is an area with a very strong division of topography, which is the basis for formation and development of different types of vegetation such as broadleaf evergreen closed forest, coniferous broadleaf mixed forest, forest natural conifers, ...

In this study, using data obtained from UAV to classify a number of vegetation cover and vegetative species of canopy dominant for monsoon rain forest in Ngoc Linh Nature Reserve, Vietnam. The main purpose of this study is to analyse the characteristics of vegetation types based on plant indicators obtained from UAVs. Based on that, it can be widely used in classification study and assessment of the stability of tropical forest vegetation in similar areas.

\section{Materials and Methods}

\subsection{Study site and field data collection}

Ngoc Linh Nature Reserve is located in Kon Tum province (Figure 1) with Ngoc Linh mountain peak of $2,598 \mathrm{~m}$ high, located in a high mountain area of the Truong Son mountain range, connecting with the Quang Nam - Quang Ngai - Binh Dinh mountain circuit of Truong Son Nam. Belonging to the tropical monsoon region as well as the plateau monsoon subsystem, divided into two distinct seasons a year, this area is the origin of the major rivers including the Dak Mek River, which originates from the peak of Ngoc Linh and Dak Po Ko river from the peaks above $2000 \mathrm{~m}$ high. There is a wide diversity of vegetation types for the subtropical high mountains, which are characterized by the following groups regarding Evergreen closed broad evergreen humid forests, medium and high mountains; Evergreen closed and broad leaved and coniferous forest.

Studies in Ngoc Linh Nature Reserve have been carried out quite a lot since then, including the studies of the Institute of Ecology and Biological Resources (2004) and ones of Vietnam-Russia Tropical Centre $(2004,2006)$... However, most of them are surveying and classifying plants based on the traditional method - sampling. Remote sensing surveys, especially the use of UAVs in this area, have never been conducted. Therefore, we 
conducted a field trip in September 2019, combining the classification of vegetation types by traditional methods and using UAV Phantom 4 Advanced equipment in two forest areas typical for Conservation area.

\subsection{UAV data collection}

With the complex differentiated terrain, the take-off area is located at the mountain foot, so it is reasonable to use unmanned aerial vehicles in this area. The Phantom 4 Advanced has excellent features such as the ease of use and the ability to be transported in hilly areas due to its compact design and low weight. In addition, the use of four sensors to avoid objects that can detect objects at a distance of $30 \mathrm{~m}$ is very suitable for areas with divided terrain such as Ngoc Linh Nature Reserve. Equipped with a 20 MP camera, capturing images in the visible light range (from about $380-760 \mathrm{~nm}$ ), it allows the necessary data for the analysis of TGI and VARI indicators for vegetative cover.

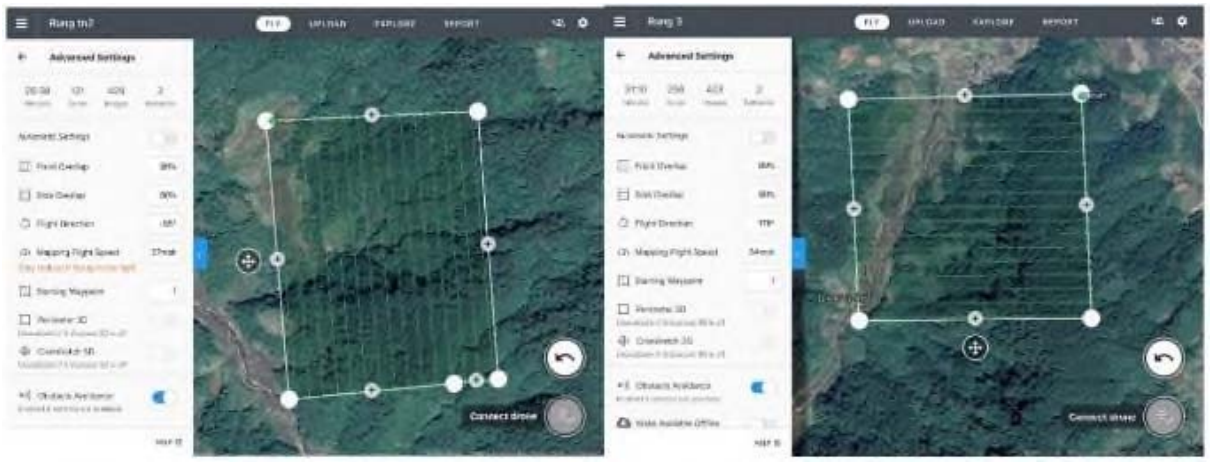

Fig. 2. Flight scheduling on DroneDeploy software.

Based on DroneDeploy software of IOS, we set 2 flight parameters for 2 areas as shown in Figures 1 and 2. In particular, area 1 with an area of 131 Acres, area 2 has 256 Acres with image coverage (Overlap) reaching $90 \%$ to ensure the best image quality and image processing. The two selected areas have terrain elevations above 1,000 $\mathrm{m}$, which have similarities in the variety of vegetation types. The collected UAV data is processed by Pix4Dmapper Pro 2019 software.

After processing, we combine images to create multi-spectral images, continue processing the TGI and VARI indexes by the image processing software UAV Pix4D according to the following formulas:

$$
\begin{gathered}
\text { VARI }=\left(\mathbf{R}_{\text {green }}-\mathbf{R}_{\text {red }}\right) /\left(\mathbf{R}_{\text {green }}+\mathbf{R}_{\text {red }}-\mathbf{R}_{\text {blue }}\right)[21] \\
\text { TGI }=\mathbf{R}_{\text {green }}-\left(\mathbf{0 . 3 9} * \mathbf{R}_{\text {red }}\right)-\left(\mathbf{0 . 6 1} * \mathbf{R}_{\text {blue }}\right)[24]
\end{gathered}
$$

In which: $\mathrm{R}_{\text {blue }}$ : $480 \mathrm{~nm}$ wavelength; $\mathrm{R}_{\text {green }}: 550 \mathrm{~nm}$ Wavelength; $\mathrm{R}_{\text {red }}: 670 \mathrm{~nm}$ wavelength. 


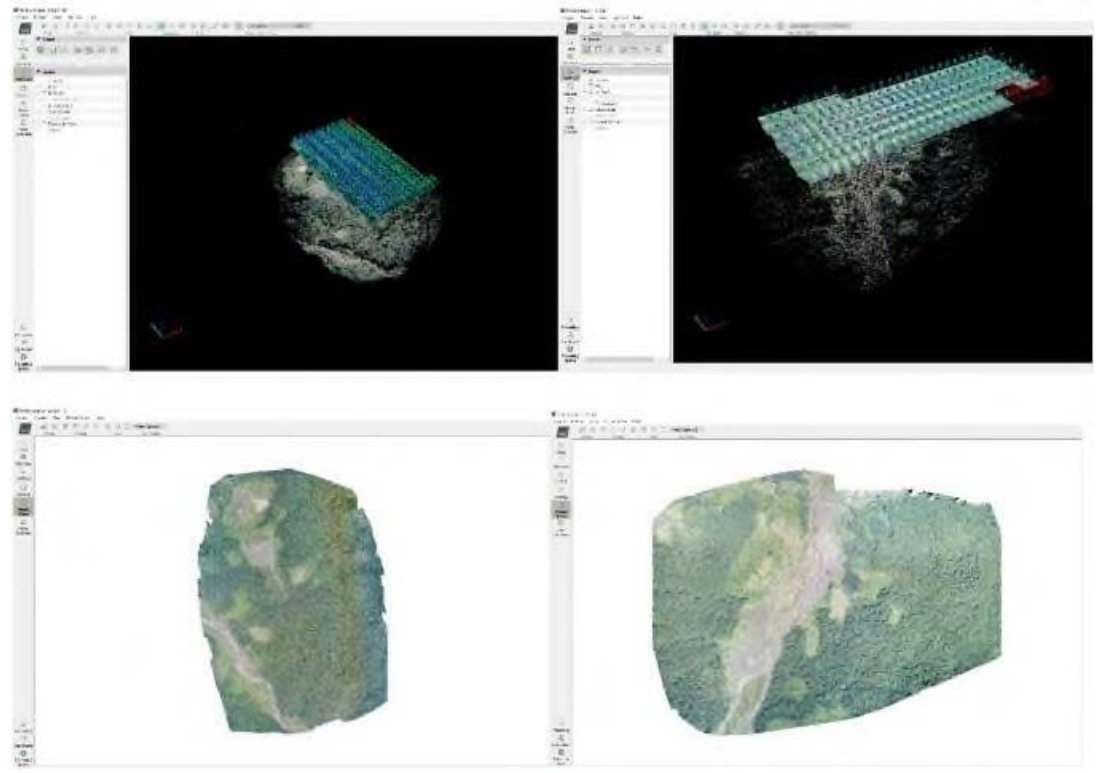

Fig. 3. Image processing on Pix4Dfield software.

From the results obtained after analysing the VARI and TGI index in the typical vegetation, statistical methods of calculation, variance and standard deviation were used to determine the dispersion of VARI values and TGI according to the average values by the following formula:

$$
\boldsymbol{S}^{\mathbf{2}}=\frac{\boldsymbol{\Sigma}_{\boldsymbol{i}}^{\boldsymbol{n}}\left(\boldsymbol{X}_{\boldsymbol{i}}-\overline{\boldsymbol{X}}\right)^{\mathbf{2}}}{\boldsymbol{n}-\mathbf{1}} \quad \boldsymbol{S}=\sqrt{\frac{\sum(x-\bar{x})^{2}}{n-1}}
$$

Explanation:

$\mathrm{n}$ is the number of elements in the dataset

$\bar{X}$ is the average value of the dataset

$\mathrm{x}_{\mathrm{i}}$ is the value of the dataset.

Variations and standard deviations are an important value in assessing the dispersion of VARI and TGI values in each specific plant community, thereby serving as a basis for assessing the sustainability of the plant community.

\section{Results}

Based on the data collected from UAV, the TGI and VARI plant indicators of the two areas were processed and analysed. The results are shown in Fig. 4, 5 and 6.

Based on the topographic and geologic characteristics, as well as the slope in each area, different types of plant communities have been divided. The results are shown in Figures 7 , 8 and Tables 1,2 . 


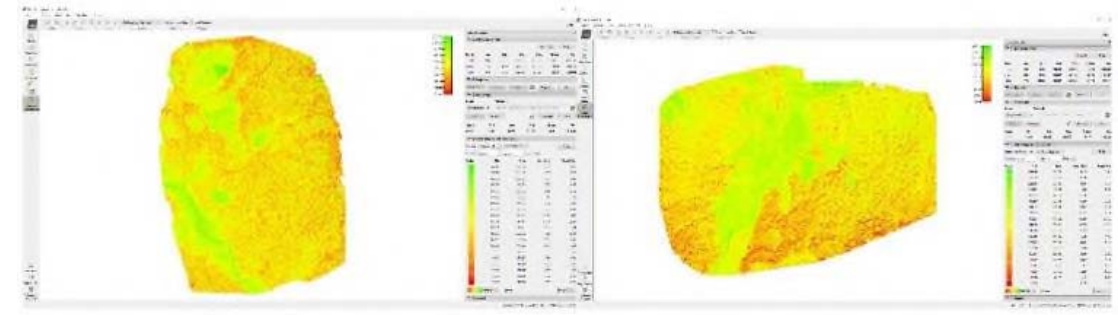

(a)

(b)

Fig. 4. DSM model in mixed forest area: a. Region 1; b. Region 2.

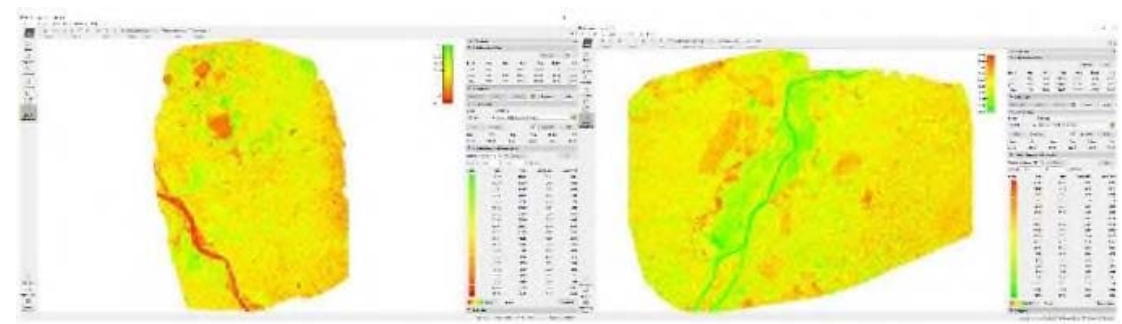

(a)

(b)

Fig. 5. TGI of mixed forest area: a. Region 1; b. Region 2.

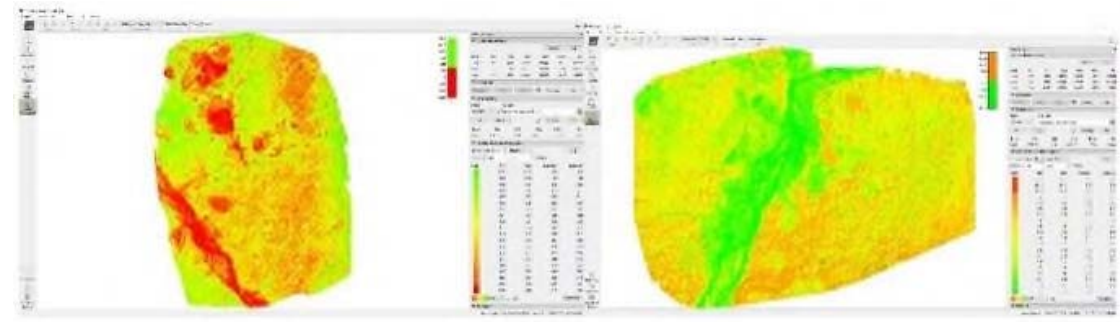

(a)

(b)

Fig. 6. VARI of mixed forest area: a. Region 1; b. Region 2.

In this research, the symbols for the plant communities can be listed as follows: (a): Evergreen broad leaved forest; (b): Mixed forest (broadleaf and ); (c): Coniferous forest of Pinus kesyia; (d): Restoration forest; (e): Grassland and scrub; (f) Annual crops ; (g): Plantation forest.

Based on the results of analysing the plant index of TGI and VARI in the two surveyed areas by UAV, reflected in Figures 5 and 6 combined with the classification of plant communities as above, the results obtained were shown in tables 3 and 4 below.

Based on data from tables 3 and 4, comparing the average values and standard deviations of the TGI and VARI indices in each group of plant communities, it can be noticed that the differences are quite large, reflecting exactly the nature of each plant community according to the laws of nature and under the influence of humans. 


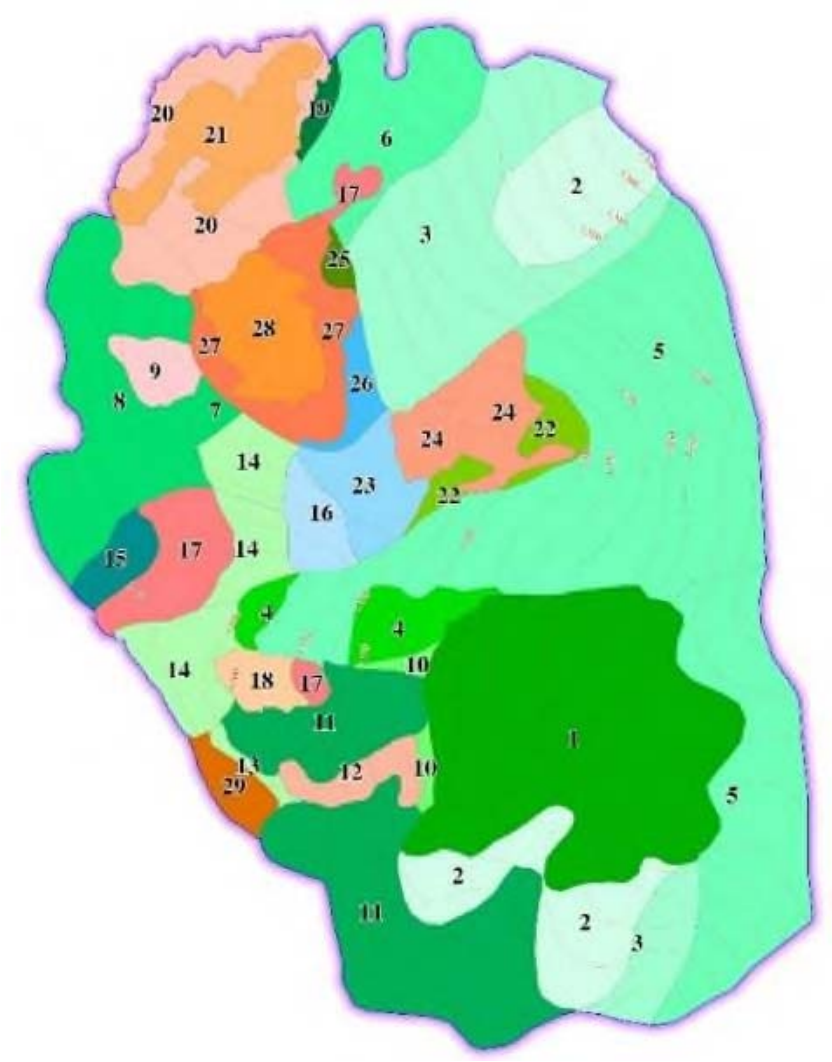

Fig. 7. Classification of regional plant in region 1.

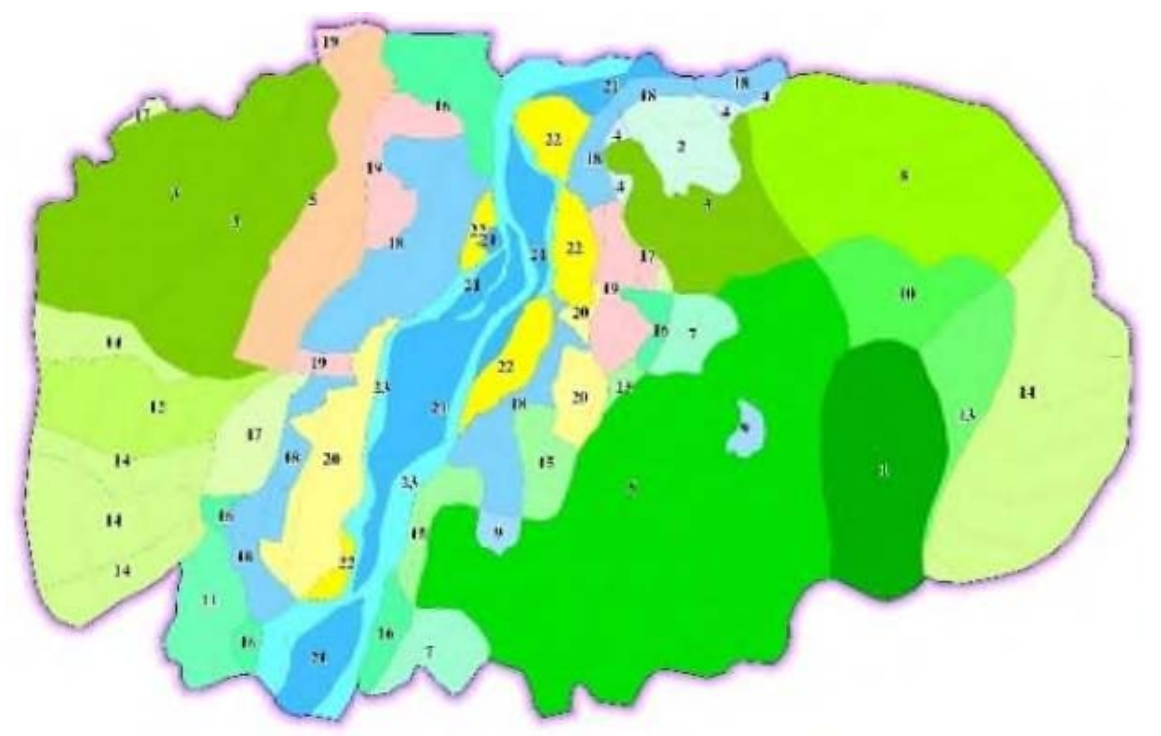

Fig. 8. Classification of regional plant in the Region 2. 
Table 1. Explanation on classification of plant communities according to natural conditions in region 1.

\begin{tabular}{|c|c|c|c|c|c|c|c|c|}
\hline \multirow[t]{2}{*}{ Type of soil } & \multirow{2}{*}{$\begin{array}{l}\text { Geomorphologic } \\
\text { characteristics }\end{array}$} & \multirow[t]{2}{*}{ Slope } & \multicolumn{4}{|c|}{ Natural vegetation } & \multicolumn{2}{|c|}{$\begin{array}{c}\text { Anthropogenic } \\
\text { vegetation }\end{array}$} \\
\hline & & & (b) & (d) & (c) & (e) & (g) & (f) \\
\hline \multirow{10}{*}{$\begin{array}{l}\text { Alumi- } \\
\text { Humic } \\
\text { Acrisols }\end{array}$} & $\begin{array}{l}\text { The erosed flat peak is } 1200 \\
-1400 \mathrm{~m} \text { high, Early Miocene }\end{array}$ & $30-45$ degrees & 1 & 2 & & & & \\
\hline & $\begin{array}{l}\text { The walls and the ribs were } \\
\text { eroded, the Fourth did not } \\
\text { divide }\end{array}$ & $>45$ degrees & & 3 & & & & \\
\hline & $\begin{array}{l}\text { The walls and the ribs were } \\
\text { eroded, the Fourth did not } \\
\text { divide }\end{array}$ & 30 - 45 degrees & 4 & 5 & & & & \\
\hline & $\begin{array}{l}\text { The walls and the ribs were } \\
\text { eroded, the Fourth did not } \\
\text { divide }\end{array}$ & 25 - 30 degrees & & 6 & & & & \\
\hline & $\begin{array}{l}\text { Cliffs and ribs of gravity, the } \\
\text { Fourth does not divide }\end{array}$ & $>45$ degrees & & 7 & 8 & & 9 & \\
\hline & $\begin{array}{l}\text { Cliffs and ribs of gravity, the } \\
\text { Fourth does not divide }\end{array}$ & 30 - 45 degrees & 10 & 11 & & & 12 & 13 \\
\hline & $\begin{array}{l}\text { Cliffs and ribs of gravity, the } \\
\text { Fourth does not divide }\end{array}$ & 25 - 30 degrees & 14 & & 15 & 16 & 17 & 18 \\
\hline & $\begin{array}{l}\text { Cliffs and ribs of gravity, the } \\
\text { Fourth does not divide }\end{array}$ & 15 - 25 degrees & & 19 & & & 20 & 21 \\
\hline & $\begin{array}{l}\text { Cliffs and ribs of gravity, the } \\
\text { Fourth does not divide }\end{array}$ & 8 - 15 degrees & & 22 & & 23 & 24 & \\
\hline & $\begin{array}{l}\text { Cliffs and ribs of gravity, the } \\
\text { Fourth does not divide }\end{array}$ & 3 - 8 degrees & & 25 & & 26 & 27 & 28 \\
\hline $\begin{array}{c}\text { Hapli- } \\
\text { Umbric } \\
\text { Gleysols }\end{array}$ & $\begin{array}{l}\text { Bottom of the valley is } \\
\text { erosed - accumulated, late } \\
\text { Holocene }\end{array}$ & 0 - 3 degrees & & & & & & 29 \\
\hline
\end{tabular}

The broadleaf evergreen forest (a): is the group of plant communities with great stability in the TGI index, when the value ranges from 16 to 17. Similarly, the VARI index of this group also fluctuated gradually, from 0.14 to 0.19 . This is explained by the fact that this community is a highly stable community group in the area, less affected by humans, and is in the growing season, so the density of flowering is quite high. Therefore, the plant indicators are always quite stable but have low value.

For the mixed forest (broadleaf and coniferous) (b): VARI and TGI are quite similar for the two areas, with VARI index ranging from 0.15 to 0.28 ; in which the TGI index fluctuates between 15 and 20. This is a group of communities that are not influenced by humans, still retaining the development according to the natural law. Therefore, the similarity of the two areas is obvious.

Comparing the standard deviation of the TGI in the two areas, we can see the similarity in the fluctuations. However, Area 2 experiences a lower fluctuation rate, with a smaller standard deviation value, so it is possible to comment on the stability of the mixed broadleaf coniferous forest community in the Area 2 is greater than Area 1. However, when comparing the standard deviation of the VARI index, it can be seen that the fluctuations of both regions are quite large, especially Area 1. This is affected by the increase in the growth of broadleaf plants in the middle of the rainy season, with broadleaf populations in the flowering period, mixed with conifers (Pinus kesyia). 
Table 2. Explanation for classification of plant communities according to natural conditions in region 2.

\begin{tabular}{|c|c|c|c|c|c|c|c|c|c|}
\hline \multirow[b]{2}{*}{$\begin{array}{l}\text { Type of } \\
\text { soil }\end{array}$} & \multirow[b]{2}{*}{$\begin{array}{l}\text { Geomorphologic } \\
\text { characteristics }\end{array}$} & \multirow[b]{2}{*}{ Slope } & \multicolumn{4}{|c|}{ Natural vegetation } & \multicolumn{2}{|c|}{$\begin{array}{c}\text { Anthropogenic } \\
\text { vegetation }\end{array}$} & \multirow{2}{*}{$\begin{array}{c}\begin{array}{c}\text { Aquatic } \\
\text { System }\end{array} \\
\text { River and } \\
\text { small streams }\end{array}$} \\
\hline & & & (a) & (b) & (c) & (d) & (e) & (f) & \\
\hline \multirow{7}{*}{$\begin{array}{l}\text { Alumi- } \\
\text { Humic } \\
\text { Acrisols }\end{array}$} & $\begin{array}{l}\text { The erosed flat peak is } \\
1200-1400 \mathrm{~m} \text { high, } \\
\text { Early Miocene }\end{array}$ & $\begin{array}{l}30-45 \\
\text { degrees }\end{array}$ & 1 & & & & & & \\
\hline & $\begin{array}{l}\text { The walls and the ribs } \\
\text { were eroded, the } \\
\text { Fourth did not divide }\end{array}$ & $\begin{array}{l}25-30 \\
\text { degrees }\end{array}$ & & 2 & 3 & 4 & 5 & & \\
\hline & $\begin{array}{l}\text { The walls and the ribs } \\
\text { were eroded, the } \\
\text { Fourth did not divide }\end{array}$ & $\begin{array}{l}30-45 \\
\text { degrees }\end{array}$ & 6 & 7 & 8 & 9 & & & \\
\hline & $\begin{array}{l}\text { The walls and the ribs } \\
\text { were eroded, the } \\
\text { Fourth did not divide }\end{array}$ & $\begin{array}{c}>45 \\
\text { degrees }\end{array}$ & 10 & & & & & & \\
\hline & $\begin{array}{l}\text { The walls and the ribs } \\
\text { were eroded, the } \\
\text { Fourth did not divide }\end{array}$ & $\begin{array}{l}25-30 \\
\text { degrees }\end{array}$ & & 11 & & & & & \\
\hline & $\begin{array}{l}\text { The walls and the ribs } \\
\text { were eroded, the } \\
\text { Fourth did not divide }\end{array}$ & $\begin{array}{l}30-45 \\
\text { degrees }\end{array}$ & & & 12 & & & & \\
\hline & $\begin{array}{l}\text { The walls and the ribs } \\
\text { were eroded, the } \\
\text { Fourth did not divide }\end{array}$ & $\begin{array}{c}>45 \\
\text { degrees }\end{array}$ & 13 & & 14 & & & & \\
\hline $\begin{array}{l}\text { Hapli- } \\
\text { Chromic } \\
\text { Acrisols }\end{array}$ & $\begin{array}{l}\text { Alluvial ground, late } \\
\text { Holocene }\end{array}$ & $\begin{array}{c}3-8 \\
\text { degrees }\end{array}$ & 15 & 16 & 17 & 18 & 19 & 20 & \\
\hline $\begin{array}{l}\text { Hapli- } \\
\text { Umbric } \\
\text { Gleysols }\end{array}$ & $\begin{array}{l}\text { Bottom of the valley is } \\
\text { erosed - accumulated, } \\
\text { late Holocene }\end{array}$ & $\begin{array}{c}0-3 \\
\text { degrees }\end{array}$ & & & & 21 & & 22 & \\
\hline & Aquatic system & & & & & & & & 23 \\
\hline
\end{tabular}

Coniferous forest of Pinus kesyia (c): The TGI index between the two areas is quite similar, ranging from 15 to 20 . Meanwhile, the VARI index is not significantly different. This reflects the similarity of the Pinus kesyia vegetation that dominated in the two survey areas, where they were similar in height, similar species composition, rib directions and similar terrain conditions.

For standard deviations, there is a similarity in the standard deviation index for TGI and VARI between coniferous forest communities in this group. Due to the stability at the time of the survey of coniferous forest communities, they show quite similar values.

Restoration forest (d): Similar to the two plant groups b and c, the TGI index has a large similarity, ranging from 16 to 22 . However, the VARI index has a variation in both areas. Because September is in the middle of the rainy season, it is the flowering season of some broadleaf trees. Therefore, differences between species composition and growth rates are the main causes leading to fluctuations in VARI index in the two study areas. 
Table 3. Summary of TGI and VARI indicators in Region 1.

\begin{tabular}{|c|c|c|c|c|c|c|c|c|c|}
\hline 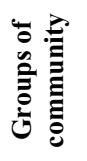 & 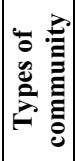 & 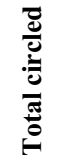 & 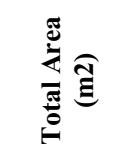 & 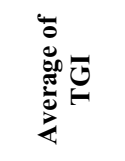 & U్ & U & 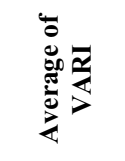 & 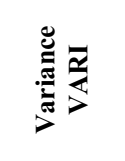 & 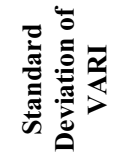 \\
\hline (b) & 1 & 180 & 82986.92 & 17.44775 & 31.96463 & 5.653727 & 0.145317 & 0.003754 & 0.061269 \\
\hline (b) & 4 & 173 & 10649.52 & 17.60772 & 38.10717 & 6.173101 & 0.159481 & 0.003501 & 0.059166 \\
\hline (b) & 10 & 220 & 2519.43 & 17.74519 & 41.21416 & 6.419825 & 0.160555 & 0.003083 & 0.055521 \\
\hline (b) & 14 & 143 & 24122.96 & 16.35746 & 38.55579 & 6.209331 & 0.195972 & 0.005034 & 0.070947 \\
\hline (c) & 8 & 226 & 38237.54 & 15.28624 & 47.353 & 6.881352 & 0.289287 & 0.023756 & 0.15413 \\
\hline (c) & 15 & 163 & 5176.31 & 14.85921 & 37.95716 & 6.160938 & 0.201637 & 0.002425 & 0.049243 \\
\hline (d) & 2 & 48 & 42970.13 & 18.79643 & 45.99205 & 6.781744 & 0.11887 & 0.003171 & 0.056311 \\
\hline (d) & 3 & 158 & 63030.07 & 18.9405 & 48.22478 & 6.944406 & 0.194041 & 0.008171 & 0.090391 \\
\hline (d) & 5 & 132 & 138418.2 & 14.60037 & 50.67894 & 7.118914 & 0.230257 & 0.019214 & 0.138616 \\
\hline (d) & 6 & 79 & 24887.18 & 18.08829 & 45.03174 & 6.71057 & 0.253576 & 0.007584 & 0.087085 \\
\hline (d) & 7 & 169 & 2218.94 & 15.56749 & 76.51826 & 8.747472 & 0.279642 & 0.013022 & 0.114114 \\
\hline (d) & 11 & 109 & 59026.54 & 15.70805 & 34.07386 & 5.837282 & 0.14908 & 0.003797 & 0.061623 \\
\hline (d) & 19 & 71 & 1955.06 & 19.63967 & 75.31787 & 8.678587 & 0.222524 & 0.010346 & 0.101713 \\
\hline (d) & 22 & 161 & 6812.66 & 20.29184 & 47.55857 & 6.896272 & 0.199441 & 0.00389 & 0.062373 \\
\hline (d) & 25 & 91 & 1531.87 & 18.57339 & 45.25229 & 6.726982 & 0.232584 & 0.006473 & 0.080458 \\
\hline (e) & 16 & 126 & 6325.21 & 18.00961 & 42.01532 & 6.481923 & 0.170374 & 0.003722 & 0.061005 \\
\hline (e) & 23 & 158 & 10128.67 & 17.54691 & 63.97257 & 7.998286 & 0.157635 & 0.006814 & 0.082548 \\
\hline (e) & 26 & 46 & 3975.22 & 17.71371 & 48.8659 & 6.990415 & 0.221 & 0.007679 & 0.087631 \\
\hline (f) & 13 & 90 & 1440.21 & 24.01642 & 76.46921 & 8.744667 & 0.105821 & 0.00312 & 0.055859 \\
\hline (f) & 18 & 167 & 4549.1 & 21.70603 & 21.29984 & 4.615175 & 0.027882 & 0.001463 & 0.038243 \\
\hline (f) & 21 & 116 & 14938.17 & 13.8716 & 73.71204 & 8.585572 & 0.050263 & 0.002965 & 0.054453 \\
\hline (f) & 28 & 127 & 9560.52 & 9.738744 & 75.11356 & 8.666808 & 0.040341 & 0.002621 & 0.051197 \\
\hline (f) & 29 & 143 & 4504.46 & 21.18174 & 54.75619 & 7.399743 & 0.056381 & 0.002465 & 0.049649 \\
\hline (g) & 9 & 171 & 5221.28 & 21.10716 & 96.98616 & 9.848155 & 0.220767 & 0.011572 & 0.107572 \\
\hline (g) & 12 & 72 & 6015.68 & 22.45027 & 87.25713 & 9.341153 & 0.144596 & 0.002739 & 0.052332 \\
\hline (e) & 17 & 108 & 15966.49 & 26.43816 & 52.67254 & 7.257585 & 0.136729 & 0.004161 & 0.06451 \\
\hline (g) & 20 & 171 & 23413.82 & 23.66571 & 94.40116 & 9.716026 & 0.147008 & 0.007636 & 0.087387 \\
\hline (f) & 24 & 82 & 16032.84 & 22.93143 & 100.3234 & 10.01616 & 0.124272 & 0.005624 & 0.074995 \\
\hline (f) & 27 & 64 & 14339.59 & 26.8518 & 101.4677 & 10.07312 & 0.141384 & 0.006115 & 0.078199 \\
\hline
\end{tabular}

The standard deviations for the TGI index are similar in both areas, indicating the stability of the plant communities in this group. However, due to the different density of broadleaf tree species in the reproductive period in the communities, VARI standard deviation is quite large.

Grasslands and scrubs (e): TGI and VARI indices show uneven variation between Areas 1 and 2. While in Area 1 there is a certain stability (ranging from 20-28 for the TGI and 0.12 to 0.2 for the VARI), the volatility in Area 2 is relatively large. . The TGI index in area 2 is highly volatile, while the VARI index plummets in respects of types of community. It can be seen that the grasslands and shrub communities in Area 2 are greatly affected by simultaneous farming activities of people and from natural processes when the area is regularly flooded and subjected to Impact of floods during the rainy season in this area. In region 1 is a place with high terrain, no river system, only affected by 2 households living and farming here. Due to frequent human influences, the vegetation of this group has large fluctuations of standard deviation. 
Table 4. Summary of TGI and VARI indicators in Region 2.

\begin{tabular}{|c|c|c|c|c|c|c|c|c|c|}
\hline 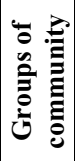 & 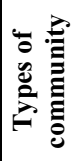 & 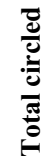 & 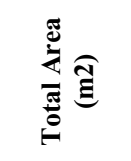 & 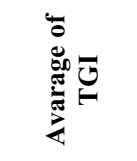 & Uू & 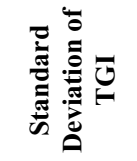 & 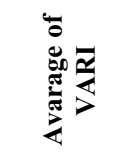 & 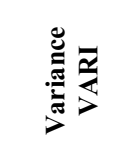 & 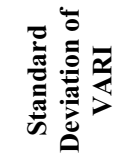 \\
\hline (a) & 1 & 150 & 37557.08 & 20.34351 & 40.29688 & 6.347982 & 0.195128 & 0.010964 & 0.104709 \\
\hline (a) & 6 & 126 & 145253.8 & 16.31345 & 52.42087 & 7.240226 & 0.240831 & 0.01751 & 0.132324 \\
\hline (a) & 10 & 156 & 17556.99 & 19.98503 & 33.64852 & 5.800735 & 0.174679 & 0.0092 & 0.095916 \\
\hline (a) & 13 & 93 & 14374.92 & 19.6193 & 33.47853 & 5.786063 & 0.17725 & 0.009824 & 0.099118 \\
\hline (a) & 15 & 130 & 14716.26 & 14.87383 & 44.79887 & 6.693196 & 0.226302 & 0.01466 & 0.121077 \\
\hline (b) & 2 & 190 & 11941.17 & 17.04985 & 46.30916 & 6.805084 & 0.188166 & 0.00746 & 0.086373 \\
\hline (b) & 7 & 132 & 15419.13 & 22.78455 & 55.45968 & 7.447126 & 0.185572 & 0.013596 & 0.116602 \\
\hline (b) & 11 & 160 & 12818.68 & 15.67596 & 53.20155 & 7.293939 & 0.178684 & 0.012449 & 0.111576 \\
\hline (b) & 16 & 94 & 23801.15 & 18.15048 & 61.08443 & 7.815653 & 0.132926 & 0.010739 & 0.103627 \\
\hline (c) & 3 & 114 & 133321.6 & 15.21919 & 106.4414 & 10.31704 & 0.15014 & 0.014215 & 0.119226 \\
\hline (c) & 8 & 149 & 62912.04 & 19.25243 & 31.23332 & 5.588677 & 0.171317 & 0.004662 & 0.068281 \\
\hline (c) & 12 & 108 & 22420.26 & 17.12451 & 26.11346 & 5.110133 & 0.166747 & 0.000756 & 0.027491 \\
\hline (c) & 14 & 105 & 87234.22 & 19.37134 & 41.83563 & 6.468047 & 0.200799 & 0.00828 & 0.090992 \\
\hline (c) & 17 & 169 & 11560.02 & 16.36524 & 37.29583 & 6.107032 & 0.167736 & 0.005703 & 0.075515 \\
\hline (d) & 4 & 137 & 2638.56 & 11.20928 & 51.93073 & 7.206298 & 0.167095 & 0.017604 & 0.132681 \\
\hline (d) & 9 & 166 & 4128.23 & 27.94338 & 5.536102 & 2.352892 & 0.123207 & 0.006774 & 0.082307 \\
\hline (d) & 18 & 124 & 60116.8 & 19.15061 & 86.49471 & 9.300253 & 0.071303 & 0.004434 & 0.066586 \\
\hline (d) & 21 & 181 & 40496.13 & 9.163613 & 69.00581 & 8.306974 & 0.017745 & 0.00107 & 0.032714 \\
\hline (e) & 5 & 159 & 28021.36 & 24.54502 & 43.56711 & 6.600538 & 0.096782 & 0.002784 & 0.052768 \\
\hline (e) & 19 & 94 & 24216.45 & 18.00427 & 66.49147 & 8.15423 & 0.139203 & 0.006023 & 0.077606 \\
\hline (f) & 20 & 73 & 27631.35 & 6.830169 & 63.09017 & 7.942932 & 0.01323 & 0.000962 & 0.03102 \\
\hline (f) & 22 & 56 & 22423.3 & 2.649111 & 16.44227 & 4.054906 & 0.00546 & 0.000323 & 0.017969 \\
\hline
\end{tabular}
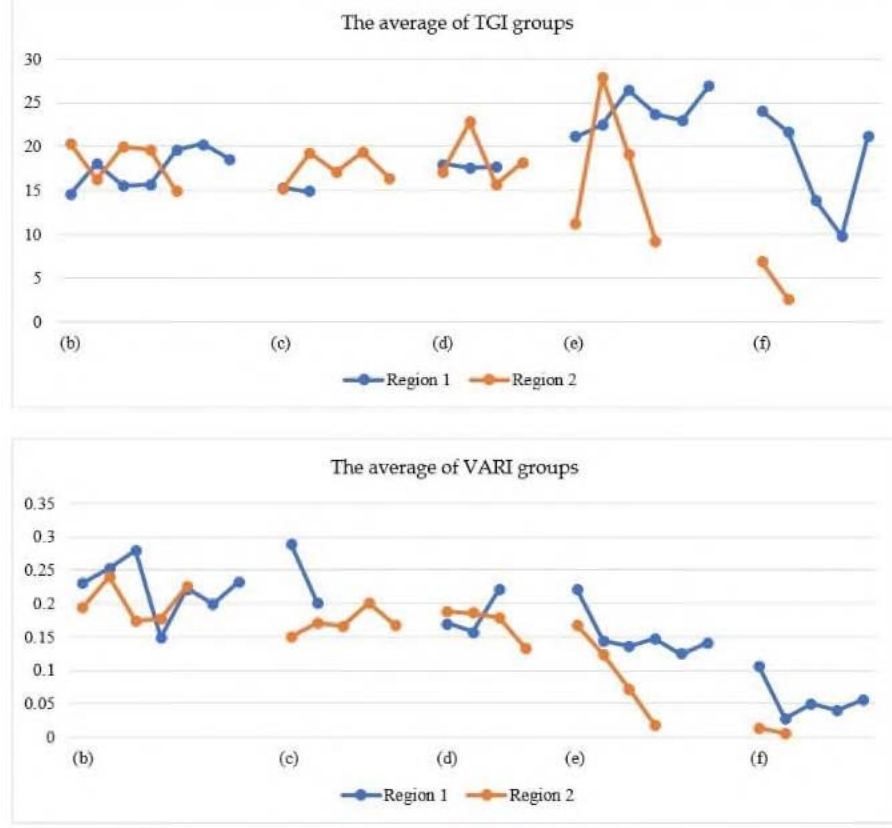

Fig. 7. Comparison chart of average values of TGI and VARI of different types of plant community groups in 2 areas. 

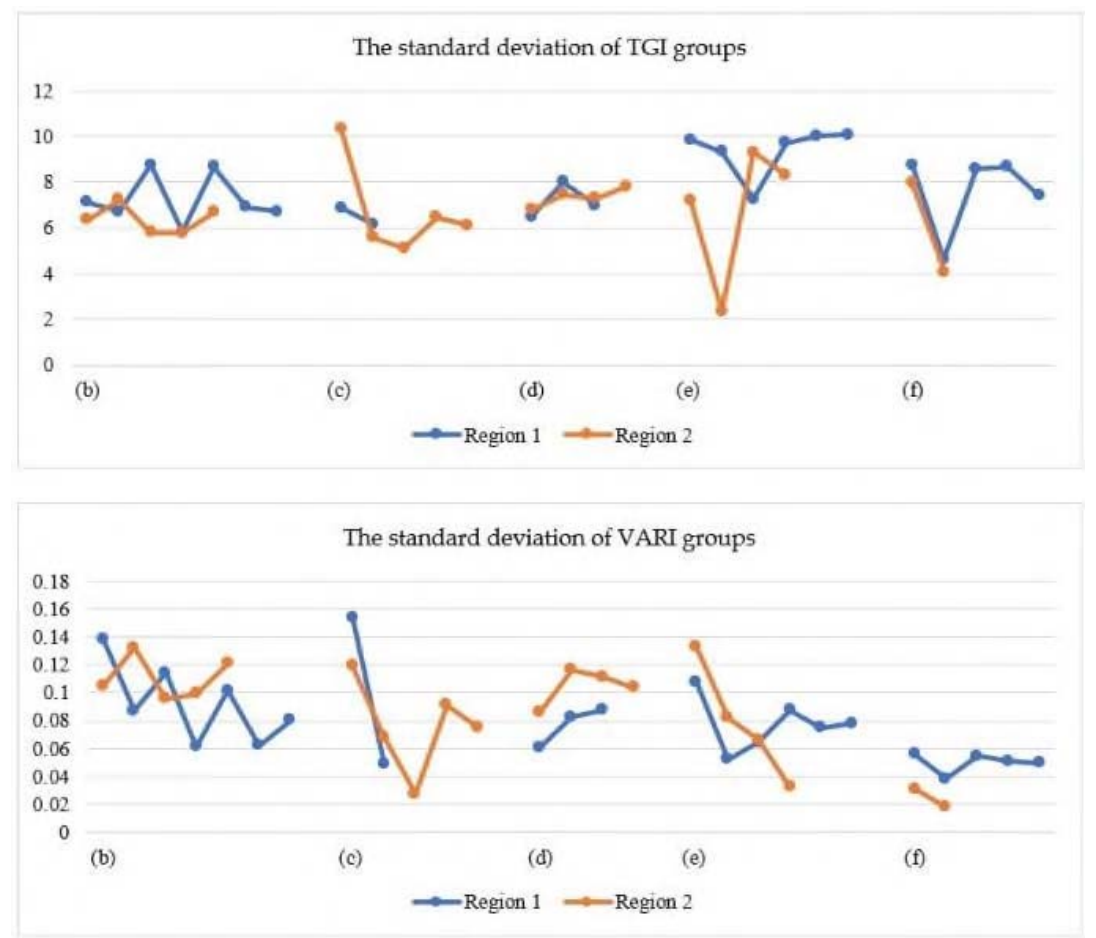

Fig. 8. Comparison chart of TGI and VARI standard deviations of different types of plant community groups in the two surveyed areas.

The group of annual crops (f): is a group that is completely affected by human, there is a big difference between the two study areas, when the TGI and VARI indicators in Area 2 are very low compared to Area 1 as well as when compared to other plant groups. However, this is quite reasonable when comparing between the two areas, with different harvesting times for agricultural crops. Area 1 has just started to be harvested, the wet rice vegetation has its location intact, so the indicators are unstable, while area 2 has been fully harvested, so the indicators tend to decrease. For this reason, the standard deviation of both the VARI and TGI indices for the agricultural tree community group in both study areas is much lower than the remaining groups.

\section{Discussion}

TGI and VARI indices are important indicators to assess the sustainability and health of plant communities, especially for vegetation strongly impacted by human activities. In the research of Tom McKinnon [24], the TGI and VARI indicators were also evaluated for an area with different types of agricultural crops. VARI and TGI indices were collected and compared with NDVI index of plants in 8 areas. However, the results did not explain the differences and fluctuations of plant indicators in each region. On the other hand, in Ashish's assessment of plant indicators for agricultural areas based on visible light strips in the UK, there are results for chlorophyll content, including the assessment of TGI and VARI indicators [25]. The results show eight different plant indicators, comparing wellcultivated and well-managed soil areas, the chlorophyll content is much higher than those that are not properly managed. Compared to a study by Jing Zhang [26] using UAV, the normalized difference vegetation index (NDVI) and VARI were evaluated for grass yield and quality in the study models to provide more effective models. Obviously, human 
influence from agricultural farming activities, has a strong impact on the development of vegetation, reflected in the assessed plant indicators. In the research of Hunt [22] analysed the TGI and calculated the standard deviation for the values obtained. The results assessed the human impact, particularly the use of nitrogen fertilizer, which greatly affected the values of the TGI. Since then, we have come up with solutions for remote sensing application to assess the TGI in the plant monitoring process, especially agricultural vegetation.

In our study, in addition to evaluating plant indicators for agricultural areas, we also evaluated some groups and types of plant community specific to tropical forests. Although the idea of using UAV in combination with evaluating TGI and VARI indicators in plant research is not new, this study has obtained quantitative research results, comparing two areas with high certain similarities in the same rainforest. The analysis shows that the big difference between the two areas is mainly in the human-impacted vegetation types, with agricultural and afforestation activities. In addition, because the locations of the two areas are different when affected by different hydrological systems, the indices for the grassland areas are also different. For coniferous forest communities, the indicators of TGI and VARI are high and stable for both areas 1 and 2. This shows the homogeneity of the growth of forest vegetation, the similarity of species composition when Pinus kesyia is the dominant plant species. In the coniferous broadleaf mixed forest areas, the stability of TGI is also clearly recorded. This is a group of communities that are less affected by humans, highly durable, less affected by natural disasters such as floods or landslides, which is easy to see the stability in the structure of each type of community in this group. For the VARI index, the data collection in the season of broad-leaved trees is in the reproductive period, making the index fluctuate quite strongly.

In the future, in particular in the next dry season, we will continue to use drones to collect data in areas where the research has already been conducted during the rainy season in 2019 at Ngoc Linh Nature Reserve. The results of the two rainy and dry seasons will be compared to assess the seasonal fluctuations of each group and plant community in this area. In addition, in order to continue to assess the annual fluctuations of tropical forest vegetation, we will continue to maintain simultaneous UAV surveys and field interviews according to the annual plan.

\section{Conclusions}

The results of the study analysed, evaluated and compared plant indicators (TGI and VARI) of specific plant groups and communities in 2 tropical forest areas of Ngoc Linh Nature Reserve, Kon Tum province, Vietnam. The parameters indicate that the stability of the natural plant community groups, including mixed broadleaf and coniferous mixed forest in both study areas, is high. VARI fluctuations in both areas are mainly due to the composition and density of broadleaf trees in the period of strong growth and reproduction. For humanimpacted plant communities, plant indicators are assessed to be uneven, largely dependent on the type of human activities, seasons and natural disasters. In particular, the group of agricultural plant communities every year has the most significant difference.

The analysis of plant indicators based on UAVs is of great significance in assessing crops, assessing vegetation strongly affected by human activities. At the same time, this is also the basis for assessing the sustainability of groups of natural vegetation affected by human. The study also opens new directions in assessing dynamics and post-vegetation, especially the differences in vegetative and reproductive stages for broadleaf and mixed leaf plant communities, as well as coniferous. This is an important basis for the management, conservation, talent development and diversity of tropical forest plants in Vietnam in the coming time. 


\section{References}

1. B. Duncan. Forests and Climate Change. (Forests and SDG13, 2019)

2. FAO. Managing forests for climate change, Strategic framework for forests and climate change. (Collaborative Partnership on Forests, 2008)

3. Secretariat of the Convention on Biological Diversity. Assessment, conservation and sustainable use of forest biodiversity. (CBD Technical Series No. 3: Montreal, France, 2001)

4. W. Susanne. Forestry, 85, 293 (2012) https://doi.org/10.1093/forestry/cps004

5. W. Han, L.I. Guang, M. Yuan, L. Zhang, Z. Shi. TCSAE 48, 139 (2017)

6. W. Han, L. Zhang, H. Zhang, Z. Shi, M. Yuan, Z. Wang. TCSAE 48, 210 (2017)

7. T.B. Habitamu, B. Ingunn. Eur. J. Remote Sens, 51, 326 (2018)

8. A. Abdelgadir; A. Rubab. RSASE, 13, 415 (2019) doi:10.1016/j.rsase.2018.12.010.

9. J. Kasper, P. Stuart, T. Martin. RSASE, 1, 36 (2015) doi: 10.1016/j.rsase.2015.06.002.

10. A.R. Robert, D. Byler, J. Eastman. Con. Bi, 29, 350 (2015) doi: 10.1111/cobi.12397.

11. B. Mukete; Y. Sun; Y. Baninla. AJAF, 5, 33 (2017) doi:10.11648/j.ajaf.20170503.11.

12. S.M.A. Jesus, G. Ioannis, C. Andrea, O. Sandra. Advances in Remote Sensing and GIS applications in Forest Fire Management from local to global assessments, in the proceedings of the 8th International EARSeL FF-SIG Workshop Stresa, 20 - 21 (2011)

Batini C., T. Blaschke, S. Lang, F. Albrecht, H.M. Abdulmutalib, Á. Barsi, G. Szabó, Zs. Kugler. Data Quality in Remote Sensing, in the International Archives of the Photogrammetry, Remote Sensing and Spatial Information Sciences, XLII-2/W7, ISPRS Geospatial Week, 18-22 (2017) https://doi.org/10.5194/isprs-archives-XLII-2W7-447-2017, 2017

13. P.D. James, M.C. Andrew, D.B. Leon, S. Chris, A.W. Serge, D.S. Jamie, H.M.S Isla, R.V. Miguel, A. Karen. Remote Sens. Ecol. Con 4, 7 (2017). doi: 10.1002/rse2.58.

14. C. Zhao. TCSAE, 45, 277 (2014)

15. H. David. Disruptive Developments in Armed UAV Technology. The United Nations Institute for Disarmament Research (2018)

16. K.B. Charles, G. Lester. Integration of Unmanned Aerial Systems Within Russian Artillery (2016)

17. J.M.P Mariana, G.S Alberto, I.J.J Sergio, E.O.C Ronald, O.D. Waldo. Int. J. Remote Sens, 40, 420 (2019) doi:10.1080/01431161.2018.1528017

18. J.L.C. Francisco; B.S. Rafael; L.G.M. María; B.G.J. Federico. Remote Sens. 11, 2564 (2019) doi:10.3390/rs11212564.

19. E.R. Hunt, C.S.T. Daughtry, J.U.H. Eitel. Agron. J 103, 1090 (2011)

20. A. Gitelson, R. Stark, U. Grits, D. Rundquist, Y. Kaufman, D. Derry. Int. J. Remote Sens 23, 2537 (2002)

21. E.R.Jr. Hunt, C.D. Paul, E.M.M. James, S.T.D. Craig, Eileen M.P., A. Bakhyt. Int. J. Appl. Earth. 21, 103 (2013)

22. W. Joanna; Y. Simeon; K. Dana

23. M.K. Tom, H. Paul. (2017)

24. K.M. Ashish, D. Pratyush. RRJoSST, 8, 30 (2019)

25. Z. Jing, V. Simerjeet, P. Wesley, K. Kevin, S. Dana, Brian S. Front. Plant Sci 10, 279 (2019) doi:10.3389/fpls.2019.00279. 